\title{
Modelling the Impact of Changes in Rainfall Distribution on the Irrigation Water Requirement and Yield of Short and Medium Duration Rice Varieties Using APSIM During Maha Season in the Dry Zone of Sri Lanka
}

\author{
R.P.R.K. Amarasingha ${ }^{*}$, L.D.B. Suriyagoda ${ }^{1}$, B. Marambe $^{1}$, L.W. Galagedara ${ }^{2}$ \\ G.L.L.P Silva ${ }^{3}$, R. Punyawardena ${ }^{4}$, R. Wijekoon ${ }^{4}$, U. Nidumolu ${ }^{5}$ and M. Howden ${ }^{6}$ \\ Postgraduate Institute of Agriculture \\ University of Peradeniya \\ Sri Lanka
}

\begin{abstract}
Rice (Oryza sativa L.) production in Sri Lanka is heavily dependent on the rainfall distribution pattern of the cultivating season. Estimation of the variation in yield and resource use efficiency of commonly grown rice varieties will be of immense importance when predicting yields under variable and changing climate. In this context, a modelling approach was used to predict the yield and water productivity of commonly grown short and medium-duration rice varieties under different climate scenarios using APSIM-Oryza module, which was previously parameterised and tested with a strong model skill. MahaIlluppallama $\left(D L_{1 B}\right)$ and Thabbowa $\left(D L_{3}\right)$ in the Dry zone of Sri Lanka were selected as the study areas. Daily rainfall data for the past 35 years (1976-2011) were analysed and the normal onset time period of Maha rains was identified in terms of a two-week period for each year, separately. The onset of rain before and after the identified weeks was considered as an early or late onset, respectively. Yield of rice varieties Bg300 (short duration; 3 months age class) and Bg359 (medium duration; 3.5 months age class) was simulated under the rainfed condition. The yield of rice varieties BG300 and Bg359 and the irrigation water requirement were simulated under two scenarios namely, (1) Normal Rainfall Distribution (NRD), and (2) Intense Rainfall Distribution (IRD). The results revealed that the amount of rainfall received during the Maha season was higher when an early onset occurred (63\% to $94 \%)$ than that observed with a late onset. Rainy season ceased by late February at both locations irrespective of the time of onset of rainfall. The simulated yield of Bg359 under the two scenarios tested (i.e. NRD and IRD) were similar. However, delayed onset would increase the irrigation water requirement by $10-17 \%$. Furthermore, a yield advantage of 14 $-51 \%$ under IRD was observed only during an early onset compared to the NRD. The results also revealed that under the IRD condition, the variability of rice yield of Bg300 was lesser irrespective of the onset compared to that of Bg359 indicating that a climate forecast for IRD during the Maha season would assist farmers to opt for short duration rice varieties compared to medium duration varieties due to lower estimated yield losses in the former.
\end{abstract}

Keywords: APSIM, intense rainfall distribution, onset of rainfall, rainfall regime

\footnotetext{
Department of Crop Science, Faculty of Agriculture, University of Peradeniya, Sri Lanka

Department of Agricultural Engineering, Faculty of Agriculture, University of Peradeniya, Sri Lanka

Department of Animal Science, Faculty of Agriculture, University of Peradeniya, Sri Lanka

Department of Agriculture, Peradeniya, Sri Lanka

Ecosystem Sciences, Commonwealth Scientific and Industrial Research Organization (CSIRO), Australia

6 Climate Adaptation Flagship, Commonwealth Scientific and Industrial Research Organization (CSIRO), Australia

Corresponding author: ruwanga.amarasingha@gmail.com
} 


\section{INTRODUCTION}

Climate change is defined as a statistically significant variation in either the mean state of climate or in its variability, persisting for an extended period (typically decades or longer). Climate change may result from natural internal earth system processes or external forcing or to persistent anthropogenic changes in the composition of the atmosphere or land use (IPCC, 2013). At present, the level of atmospheric $\mathrm{CO}_{2}$ is over $400 \mathrm{ppm}$ and as per the Bern Climate Change Model, it is projected to reach a level of $700 \mathrm{ppm}$ under climate change scenarios (Jalota et al., 2013). The average global surface temperature has also risen by $0.74 \pm 0.18{ }^{\circ} \mathrm{C}$ over the past 100 years (Trenberth and Jones, 2007). Climate change is expected to alter water resources and their distributions in time and space.

Global climate change has increased concerns on its negative and positive impacts on agricultural crops in Sri Lanka (Weerakoon and De Costa, 2009). Long term studies have shown changes in rainfall intensities with long dry spells, increasing maximum and minimum air temperatures along with increased atmospheric $\mathrm{CO}_{2}$ concentrations (IPCC, 2013). Despite these challenges, the national rice production in Sri Lanka needs to be increased to meet the increasing demand both from increasing population and changing dietary patterns.

There are two major cropping seasons in Sri Lanka, namely, Maha (Second Inter-monsoon from October to November and the North-East monsoon from December to February) and Yala (First Inter-monsoon from March to April and the South-West monsoon from May to September). Most of the rice cultivation in Sri Lanka is practiced in the Dry Zone under rainfed conditions with supplementary irrigation during the Maha season when and where necessary and mainly with supplementary irrigation during the Yala season. Previous studies have shown a significant decline in water balance (i.e. the difference between rainfall and evapotranspiration) during the Yala season in most of the climatic zones of Sri Lanka (De Costa, 2009). Analyses have also shown indications of declining water balances during the Maha season although the impact on crops may be less due to the smaller magnitudes of declines during the second inter-monsoon and the north-east monsoon. It is possible that climate change in coming decades may accelerate the declining water balances in the Maha season (De Costa, 2009). Hence, appropriate agronomic practices and proper water management techniques are imperative together with the cultivation of suitable rice varieties with greater capacity to conserve irrigation water in order to sustain production and productivity of the rice crop.

The Dry zone in Sri Lanka contributes to over $60 \%$ of the rice production in the country. The rice varieties in the short ( 3 months to mature) and medium ( 3.5 months to mature) duration age class collectively contribute to over $93 \%$ of the rice production of Sri Lanka (Agstat, 2013). Due to heavy and longer duration rainfall during the Maha season, farmers usually cultivate long and medium duration rice varieties while short duration rice varieties are cultivated during the Yala season as the availability of water is limited. The variations in onset, duration and the total amount of rainfall received during the season are important in rainfed and supplementary irrigated systems (Ayoni and Dharamasena, 2009) such as in rice cultivated during the Maha season of Sri Lanka.

In order to study the impact of changing climate, number of crop models are available in the literature (DSSAT, CropSyst, APSIM) and these models estimate crop growth, yield, water balance, and nutrient balance on daily basis. In the present study, Agricultural Production System Simulator (APSIM) is used to simulate the rice yield as affected by the changes in 
climate, soil nutrients, variety and management practices. The APSIM-Oryza module was developed by incorporating the ORYZA2000 rice growth model (Bouman and van Laar, 2006 ) to the APSIM modelling framework (Keating et al., 2003; Gaydon et al., 2012a, b). In Sri Lanka, it has been used to evaluate the nitrogen response in lowland rice (Suriyagoda and Peiris, 2013), find optimum planting date for rainfed rice (Rathnayake and Malaviarachchi, 2013) and assess the yield advantage and water productivity when aligning planting date with onset of rainfall (Amarasingha et al., 2014).

In a previous study APSIM-Oryza was parameterized and evaluated for short (Bg300) and medium (Bg359) duration rice varieties grown under standard management conditions in Sri Lanka with $14 \%$ Co-efficient of Variation (CV) for Bg300 and $8 \%$ for Bg359 (Amarasingha et al., 2014). A CV less than $20 \%$ is generally considered as a good model fit (Gaydon, 2012a, b). The validated model performed well in different agro-climatic zones in Sri Lanka under water-limited farmer-field conditions, and predicting the grain yield with a strong model skill $\left(\mathrm{R}^{2}>0.97\right.$, $\mathrm{RMSE}=484 \mathrm{~kg} \mathrm{ha}^{-1}$; Amarasingha et al., 2014). Hence, the parameterized model is robust enough to be used in the testing of performance of rice crop under possible hypothetical climatic scenarios. The objectives of this study were to (i) identify the rainfall distribution pattern and the amount of rainfall received with the changes in onset of the Maha season at two rice growing locations in Sri Lanka, (ii) evaluate the crop productivity and irrigation water requirement for a widely grown medium duration rice variety during the Maha season and (iii) use the APSIM model to assess crop productivity of medium and short duration rice varieties in a rainfed system if the rainfall distribution during the Maha season reduces and the variability increases in comparison to the present rainfall distribution pattern.

\section{METHODOLOGY}

\section{Study area}

Maha-Illuppallama (DL $\mathrm{DL}_{1 \mathrm{~b}}$, latitude $8^{\circ} 08^{\prime} 50^{\prime \prime} \mathrm{N}$ and longitude $80^{\circ} 25^{\prime} 50^{\prime}$ ' E, $137 \mathrm{~m}$ above $\mathrm{msl}$ ) and Thabbowa ( $\mathrm{DL}_{3}$, latitude $08^{\circ} 05^{\prime} 10^{\prime \prime} \mathrm{N}$ and longitude $79^{\circ} 56^{\prime} 20^{\prime}$ ' $\mathrm{E}, 32 \mathrm{~m}$ above $\mathrm{msl}$ ), located in the Dry zone of Sri Lanka were selected as the study sites. The Dry zone receives a mean annual rainfall of less than $1750 \mathrm{~mm}$ with a relatively dry season from May to September. The two sites were selected as they represent major rice growing areas in the country and highly dependent on irrigation and based on availability of long-term climate data (i.e. daily data of more than 30 years).

\section{Input data for APSIM-Oryza model}

The input data required to run the APSIM-Oryza were daily weather information, soil characteristics and crop management information, which are described below.

\section{Weather data}

Daily weather data (maximum and minimum temperatures, rainfall amount and number of sunshine hours) from January 1976 to May 2011 for Maha-Illuppallama and Thabbowa were obtained from the Natural Resource Management Center (NRMC) of the Department of Agriculture, Sri Lanka. The daily incoming radiation $\left(\mathrm{MJ} \mathrm{m}^{-2} \mathrm{~d}^{-1}\right)$ was calculated using the sunshine hours and location specific information i.e., latitude and longitude, and angstrom coefficients $(\mathrm{a}=0.29$ and $\mathrm{b}=0.39)$ (Samuel, 1991). 


\section{Soil data}

Soil characteristics of the study sites were obtained from Mapa et al. (2010; Tables 1 and 2). Layer-wise soil data were incorporated to the model where available and default values present in the model were used for sub soil layers.

Table 1. Soil physical and chemical characteristics and volumetric soil water dynamics at Maha-Illuppallama

\begin{tabular}{|c|c|c|c|c|c|c|c|c|}
\hline $\begin{array}{l}\text { Depth } \\
\text { (cm) }\end{array}$ & $\begin{array}{c}\text { BD }^{*} \\
\left(\mathrm{~g}^{-3}\right. \\
\left.\mathrm{cm}^{-3}\right)\end{array}$ & $\begin{array}{l}\text { LL15 } \\
\left(\mathrm{mm}^{-1}\right) \\
\left.\mathrm{mm}^{-1}\right)\end{array}$ & $\begin{array}{c}\text { DUL } \\
\left(\mathbf{m m}^{-1}\right) \\
\left.\mathbf{m m}^{-1}\right)\end{array}$ & $\begin{array}{c}\text { SAT } \\
\left(\mathbf{m m}^{-1}\right) \\
\left.\mathbf{m m}^{-1}\right)\end{array}$ & $\begin{array}{l}\text { OC } \\
(\%)\end{array}$ & $\begin{array}{c}E C \\
(1: 5 \mathbf{d S} \\
\left.\mathbf{m}^{-1}\right)\end{array}$ & $\begin{array}{c}\mathrm{pH} \\
(1: 5 \\
\left.\mathrm{H}_{2} \mathrm{O}\right) \\
\end{array}$ & $\begin{array}{c}\text { CEC } \\
\left(\mathrm{cmol}^{-1}\right. \\
\left.\mathrm{kg}^{-1}\right) \\
\end{array}$ \\
\hline $0-10$ & 1.7 & 0.19 & 0.31 & 0.33 & 0.91 & 0.17 & 7.6 & 10.1 \\
\hline $10-20$ & 1.7 & 0.20 & 0.31 & 0.33 & 0.91 & 0.17 & 7.6 & 10.1 \\
\hline $20-30$ & 1.7 & 0.25 & 0.32 & 0.33 & 0.91 & 0.17 & 7.6 & 10.1 \\
\hline $30-40$ & 1.5 & 0.27 & 0.35 & 0.37 & 0.20 & 0.16 & 7.8 & 11.0 \\
\hline $40-50$ & 1.5 & 0.27 & 0.35 & 0.37 & 0.20 & 0.16 & 7.8 & 11.0 \\
\hline $50-60$ & 1.5 & 0.27 & 0.35 & 0.37 & 0.20 & 0.16 & 7.8 & 11.0 \\
\hline
\end{tabular}

*BD-Bulk Density, LL-Lower Limit, DUL- Drainage Upper Limit, SAT- Saturation Water Content, OC- Organic Carbon, EC- Electrical Conductivity, CEC- Cation Exchange Capacity

Table 2. Soil physical and chemical characteristics and volumetric soil water dynamics at Thabbowa

\begin{tabular}{lcccccccc}
\hline $\begin{array}{l}\text { Depth } \\
(\mathbf{c m})\end{array}$ & $\begin{array}{c}\text { BD* } \\
(\mathbf{g} \\
\left.\mathbf{c m}^{-3}\right)\end{array}$ & $\begin{array}{c}\mathbf{L L 1 5} \\
(\mathbf{m m} \\
\left.\mathbf{m m}^{-1}\right)\end{array}$ & $\begin{array}{c}\text { DUL } \\
(\mathbf{m m} \\
\left.\mathbf{m m}^{-1}\right)\end{array}$ & $\begin{array}{c}\text { SAT } \\
(\mathbf{m m} \\
\mathbf{m m}\end{array}$ & $\begin{array}{c}\mathbf{O C} \\
(\mathbf{\%})\end{array}$ & $\begin{array}{c}\mathbf{E C} \\
(\mathbf{1 : 5} \mathbf{~ d S} \\
\left.\mathbf{m}^{-1}\right)\end{array}$ & $\begin{array}{c}\mathbf{p H}(\mathbf{1 : 5} \\
\left.\mathbf{H}_{\mathbf{2}} \mathbf{O}\right)\end{array}$ & $\begin{array}{c}\text { CEC } \\
(\mathbf{c m o l} \\
\left.\mathbf{k g}^{-\mathbf{1}}\right)\end{array}$ \\
\hline $0-10$ & 1.7 & 0.19 & 0.310 & 0.330 & 1.52 & 0.18 & 6.7 & 16.2 \\
$10-20$ & 1.5 & 0.20 & 0.310 & 0.330 & 1.40 & 0.17 & 6.8 & 13.0 \\
$20-30$ & 1.5 & 0.25 & 0.320 & 0.330 & 1.40 & 0.17 & 6.8 & 13.0 \\
$30-40$ & 1.5 & 0.27 & 0.350 & 0.370 & 1.40 & 0.17 & 6.8 & 13.0 \\
$40-50$ & 1.5 & 0.27 & 0.350 & 0.370 & 1.40 & 0.17 & 6.8 & 13.0 \\
$50-60$ & 1.5 & 0.27 & 0.350 & 0.370 & 1.40 & 0.17 & 6.8 & 13.0 \\
\hline
\end{tabular}

BD-Bulk Density, LL-Lower Limit, DUL- Drainage Upper Limit, SAT- Saturation Water Content, OC- Organic Carbon, EC- Electrical Conductivity, CEC- Cation Exchange Capacity

\section{Crop and management}

Fertilizer and management practices were identified according to the recommendations of the Department of Agriculture, Sri Lanka (DOA, 2014). Planting dates and planting method (direct seeding), irrigation and fertilizer management strategies were adjusted in the model simulations as collected from the sites.

\section{Rainfall distribution pattern}

Rainfall data for the past 35 years (1976-2011) were analysed and the onset date of Maha rains was identified for each year separately. The onset of rainfall was defined as a spell of at least $20 \mathrm{~mm}$ of rain per week in three consecutive weeks after a pre-specified week for the Maha (standard week 35) and Yala (standard week 9) seasons. Once this requirement is fulfilled, the starting day of the rainfall is considered as the date of onset (Punyawardena, 
2002; Chitranayana and Punyawardena, 2010). According to the onset dates, the average weekly rainfall was calculated for both sites. The onset was categorized into six time periods on weekly basis for the period starting from $1^{\text {st }}$ and $2^{\text {nd }}$ week of September (Sep 1-2wk) up to $1^{\text {st }}$ and $2^{\text {nd }}$ weeks of November (Nov 1-2 wk).

\section{Definition of the scenario modelled}

The rainfall distribution may change as predicted by the climate change models. One condition that would greatly affect the crop performance would be the reduction in the length of the rainfall season coupled with an increase in the intensity of rainfall (i.e. IRD: Intense Rainfall Distribution), which was considered as the first likely scenario in the modelling exercise. Continuation of the present, normal rainfall distribution (NRD) was considered as the second likely scenario in the simulation.

The IRD was defined as a $10 \%$ reduction in the total amount of rainfall towards the latter part (tail end) of the rainfall season, and the amount of arrested rainfall was proportionally incorporated to the rainy days occurred early in the season in the simulations thus, increasing the variability while keeping the total quantum of rainfall intact. Accordingly, the weather file of the APSIM model was changed. To simulate situations where supplementary irrigation was practiced, $50 \mathrm{~mm}$ irrigation was supplied in the model if the soil water content decreased below $25 \%$ of the plant available water content.

In order to evaluate the effect of supplementary irrigation on rice crop production, simulations were run with and without (i.e. rainfed) supplementary irrigated conditions. The growth of different varieties were tested (i.e. instead of the decisions on growing short or medium duration rice varieties) to be used in making management decisions to improve, maintain or minimise the reduction in yield per crop and/or water productivity under the scenarios modelled.

The calibrated APSIM version 7.4 (i.e. APSIM-ORYZA module) for Sri Lankan rice varieties (Bg300 and Bg359) was used in this study. During Maha season farmers normally cultivate the medium duration rice varieties. However, if the onset is delayed the risk of establishing medium age rice varieties increases. Therefore, in such a situation establishment of short duration rice variety may be advantageous and hence, a short duration rice variety was also used in the scenario analysis. The oryza.ini file in APSIM was modified as per the published literature (Rathnayake and Malaviarachchi, 2013; Suriyagoda and Peiris, 2013; Amarasingha et al., 2014).

\section{RESULTS AND DISCUSSION}

\section{Rainfall distribution pattern}

The rainfall distribution pattern for the 35 year period tested (1976-2011) with the onset for Maha-Illuppallama and Thabbowa study sites are illustrated in Fig. 1.

Maha-Illuppallama received 35-40\% higher rainfall during the Maha season than that Thabbowa. At Maha-Illuppallama, the onset occurred from early September in certain years while at Thabbowa the onset occurred from mid to late September. The number of rainy weeks in both sites was greater in years with an early onset than that in years with a late onset. At Maha-Illuppallama an early onset increased the amount of rainfall received by $94 \%$ 
during the season than that occurred with a late onset, and the corresponding increment at Thabbowa was $63 \%$. The rainy season eased by the late February at both locations irrespective of the time of rainfall onset.

Maha- Illuppallama

Thabbowa

Sep 1-2
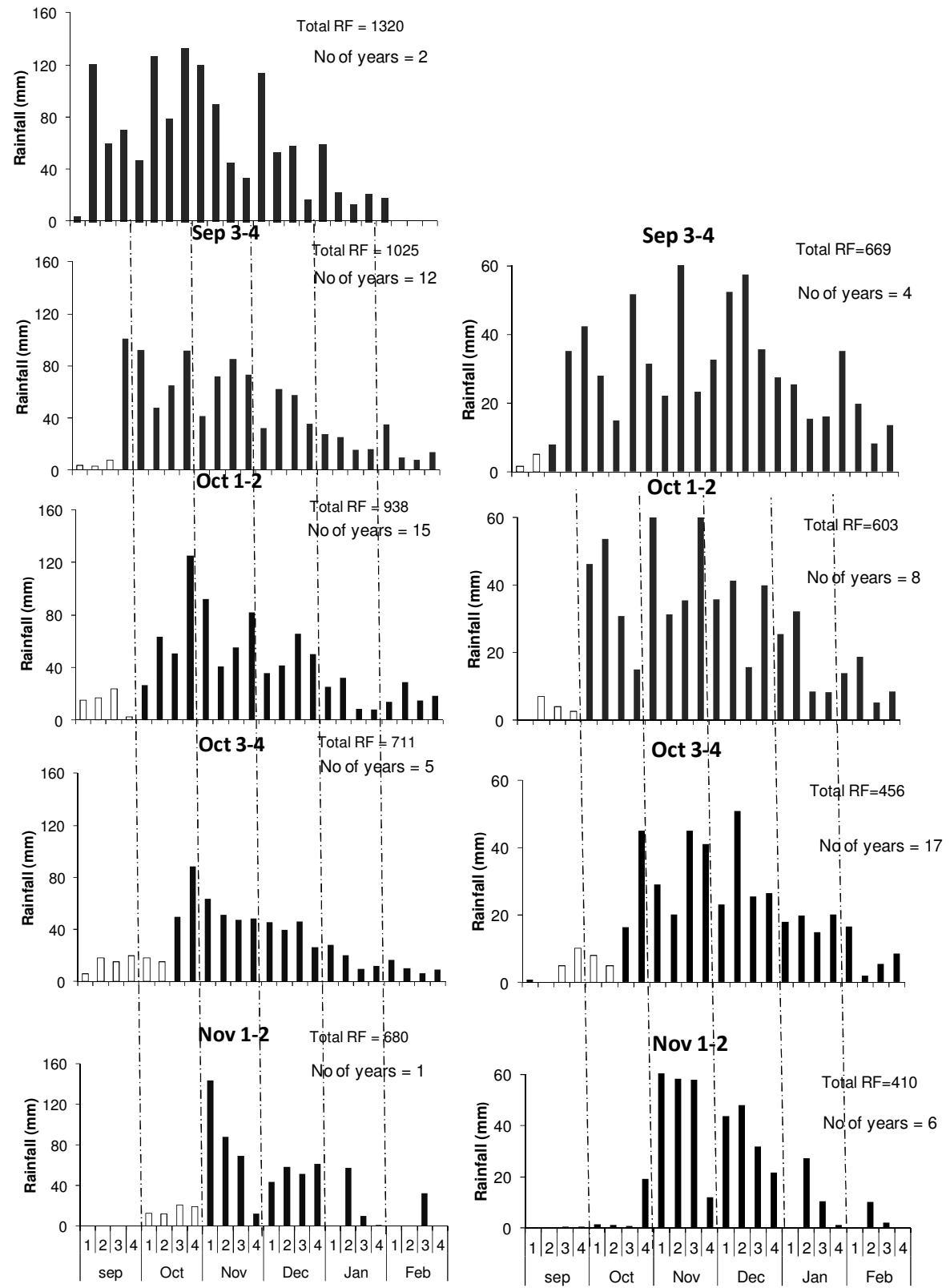

Fig.1. Distribution of rainfall during Maha with the onset at Maha-Illuppallama and Thabbowa for the last 35 years (1976-2011) 
Crop productivity and irrigation water requirement for medium duration rice variety (Bg359) during the Maha season

Fig. 2 illustrates the yield and irrigation water requirement for $\mathrm{Bg} 359$ (medium duration rice variety) during the Maha season as affected by different onset times with NRD and IRD towards the end of the season. Simulated rice yield of Bg359 was similar between the NRD and IRD scenarios when having access to supplementary irrigation, irrespective of the location and onset (Fig. 2A). Even if the rainfall distribution was reduced by $10 \%$ towards the tail with a higher intensity end (IRD scenario), having access to irrigation water ensured the crop productivity as observed under NRD scenario. However, the requirement and dependency on irrigation water differed between the two scenarios and onset. For example, in years when an early onset occurred, the amount of irrigation water required was similar between the NRD and IRD (Fig. 2B). However, when the onset was late, the amount of irrigation water required increased compared to an early onset for both the scenarios and for both sites (Fig. 2B).

The simulated results indicated that the percentage increments of irrigation water requirement at Maha-Illuppallama and Thabbowa under NRD were $88 \%$, and $53 \%$, respectively, and under IRD condition were $126 \%$ and $90 \%$, respectively. Therefore, the amount of irrigation water required under IRD scenario was higher for the medium duration rice variety $\mathrm{Bg} 359$ than that required under NRD scenario under each onset duration, i.e. at Maha-Illuppallama the increment was 10-20\% and at Thabbowa 9-25\%.
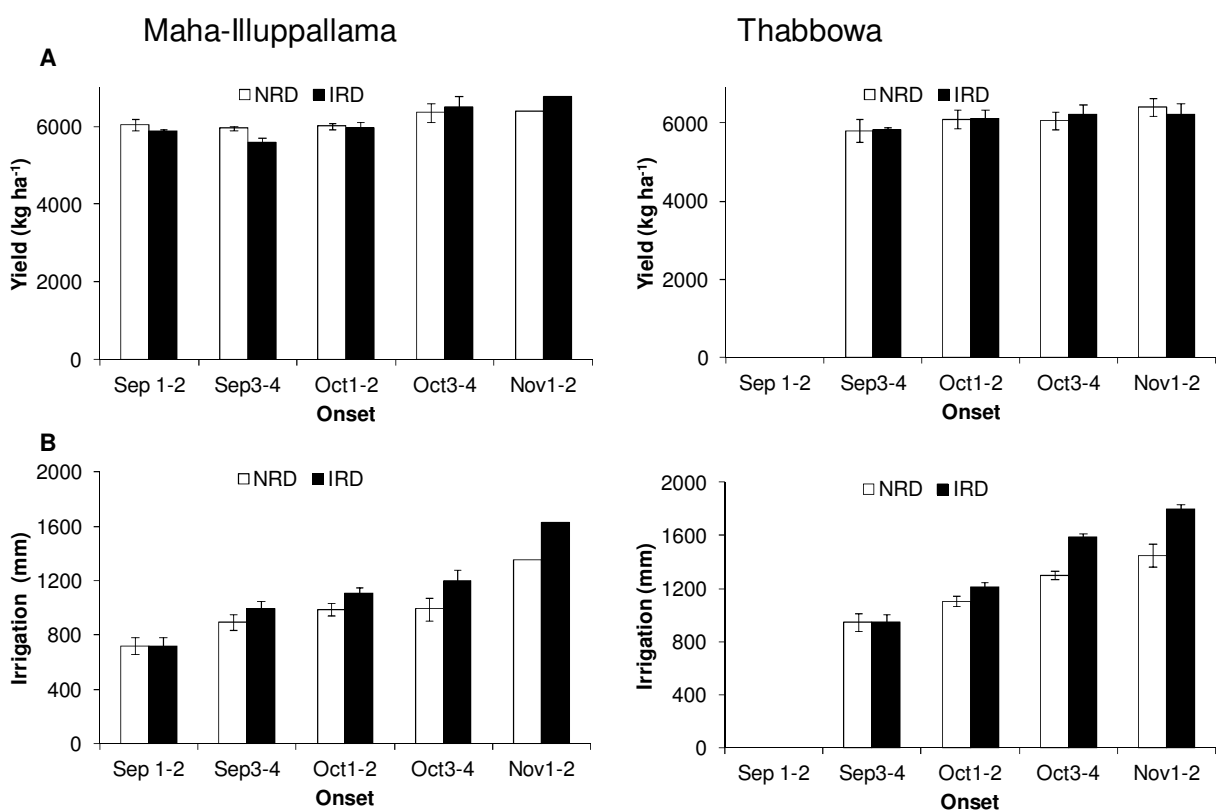

Fig. 2. (A) Yield, and (B) irrigation water requirement of Bg359 during Maha season as affected by different onset times with Normal Rainfall Distribution (NRD) and Intense Rainfall Distribution (IRD) conditions towards the end of the season when having access to supplementary irrigation at Maha-Illuppallama and Thabbowa. Vertical bars represent standard error of simulated yield and irrigation 
The simulated results indicate that the Thabbowa study site required 5-12\% more irrigation water than that at Maha-Illuppallama under both NRD and IRD scenarios. This was due to the lower amount of rainfall received at Thabbowa compared to that at Maha-Illuppallama (Fig. 1) and prevailing high evapotranspiration regime of the area. As the amount of rainfall received with an early onset was higher, the irrigation water requirement was simulated to be lower than that at a late onset at both study sites. Therefore, the dependency of supplementary irrigation water requirement increased as the onset delayed.

\section{Productivity of medium (Bg359) and short (Bg300) duration rice varieties in Maha season without the access to supplementary irrigation}

Fig. 3 illustrates the simulated yield of rice varieties $\mathrm{Bg} 359$ and $\mathrm{Bg} 300$ with the different onset times under the NRD and IRD scenarios when grown under rainfed condition at the two study sites Maha-Illuppallama and Thabbowa. With an early onset and IRD scenario, 40 $\%$ and $51 \%$ higher yield was simulated for Bg359 at Maha-Illuppallama for Sep 1-2 wk and Sep 3-4 wk onsets, respectively, compared with the NRD, which was $23 \%$ and $14 \%$ at Thabbowa in Sep 3-4 wk and Oct 1wk, respectively (Fig. 3). However, with a late onset, yield of Bg359 reduced by $28-82 \%$ under IRD scenario than that with the NRD at MahaIlluppallama and the corresponding values at Thabbowa were 15-19\%. Even under IRD with an early onset, as the rainfall season was relatively longer (than that at an late onset), the number of days with soil moisture less than the amount that can create stress (i.e. below the plant available water content- 15 bars) to the rice crop was minimum while the higher amount of rainfall received during the early growth stages of $\mathrm{Bg} 309$ minimised soil water stresses (data not shown). These resulted in a higher yield with an early onset with IRD scenario than that with NRD rainfall scenario (Fig. 3).

Moreover, the simulated yield variation of $\mathrm{Bg} 300$ at Maha-Illuppallama and Thabbowa, between the NRD and IRD was 1-20\% and $1-6 \%$, respectively (Fig. 3). The corresponding values for Bg359 at Maha-Illuppallama and Thabbowa were 28-82 \% and 15-19\%, respectively. Therefore, $\mathrm{Bg} 300$ had a lesser variability in the simulated yield both at NRD and IRD scenarios in both study sites. This response was due to the adequate soil water content maintained during the short growth of $\mathrm{Bg} 300$ than that for $\mathrm{Bg} 359$.

The present study was conducted using a well-parameterised APSIM model (Amarasingha et al., 2014; Amarasinghe and Suriyagoda 2013, 2014). Therefore, the resource requirements such as time taken to estimate the productivity was minimum for such an analysis, and the simulated results generated thorough this study are with a higher accuracy and thus, would be a valuable decision making tool at policy and practitioner levels. 
Maha-Illuppallama

Bg359

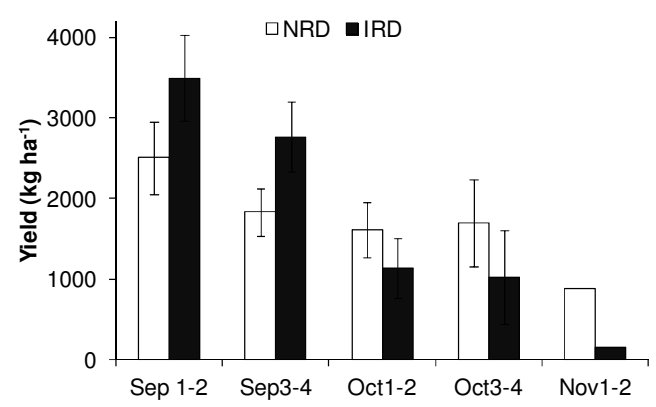

Thabbowa
$\mathrm{Bg} 300$

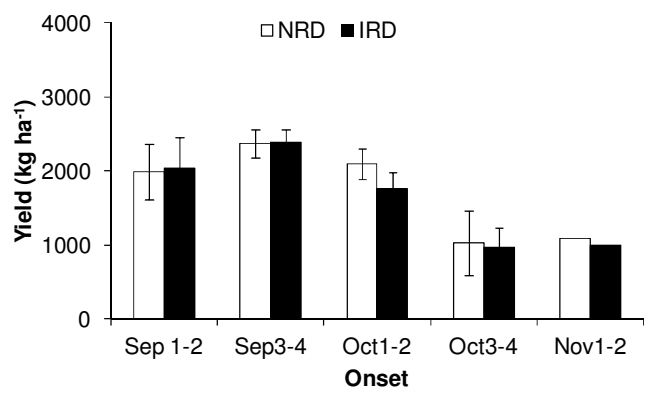

Bg300

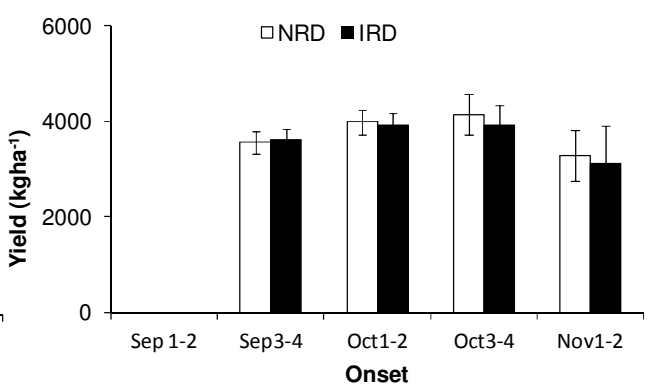

Fig. 3. Rice yield of Bg359 and Bg300 with the different onset times under the Normal Rainfall Distribution (NRD) and Intense Rain Distribution (IRD) patterns without supplementary irrigation at Maha-Illuppallama and Thabbowa. Vertical bars represent the standard error of the simulated yields.

\section{CONCLUSIONS}

An early onset resulted in a longer Maha season (i.e. early or mid-September to late February) and a higher rainfall (63\% and $94 \%$ higher at Thabbowa and Maha-Illuppallama, respectively) compared to a late onset. The well-parameterized APSIM module simulated the yield of the medium duration rice variety $\mathrm{Bg} 359$ as similar between the normal and intense rainfall distribution (IRD) scenarios when the supplementary irrigation was available. However, the irrigation water requirement increased $(90-126 \%)$ with a late onset under IRD than that with an early onset and normal rainfall distribution (NRD). The variability in rice yield of $\mathrm{Bg} 300$ was less during the Maha season even with IRD than that of $\mathrm{Bg} 359$. Availability of a seasonal climate forecast for situations such as IRD during the Maha season would assist farmers to opt for short duration rice varieties compared to medium duration varieties due to lower estimated yield losses in the former. 


\section{ACKNOWLEDGEMENTS}

The financial assistance provided by the AusAID-CSIRO project on 'Can seasonal climate forecasts improve food security in Indian Ocean Rim countries in a variable and changing climate?' (AusAID Agreement 59553) through the Agriculture Education Unit (AEU) of the Faculty of Agriculture, University of Peradeniya, Sri Lanka is gratefully acknowledged. The authors also wish to acknowledge the Natural Resources Management Centre (NRMC), Department of Agriculture for provision of daily weather data free of charge.

\section{REFERENCES}

AgStat (2013). Socio Economics and Planning Centre, Department of Agriculture, Sri Lanka.

Amarasingha, R.P.R.K. and Suriyagoda, L.D.B. (2013). Evaluation of new fertilizer recommendation for $\mathrm{Bg} 300$ in Dry zone through modelling approach. Proceeding of International Symposium on Agriculture and Environment 2013. pp 217- 221, University of Ruhuna, Matara, Sri Lanka.

Amarasingha, R.P.R.K. and Suriyagoda, L.D.B. (2014). Evaluation of new fertilizer recommendation for Bg300 and Bg359 in Dry zone through modelling approach. Proceeding of Symposium on the Young Scientist Forum 2014, 12 - 15.

Amarasingha, R.P.R.K., Galagedara, L.W., Marambe, B., Silva, G.L.L.P., Punyawardena, R., Nidumolu, U., Howden, M. and Suriyagoda, L.D.B. (2014). Aligning sowing dates with onset of rains improve rice yields and water productivity: Modelling Oryza sativa L. in Maha season in the dry zone of Sri Lanka. Tropical Agriculture Research, 25(3); 277 - 286.

Ayoni, V.D.N. and Dharmasena, A.A.H.S.K. (2009). Effect on onset, length and amount of rainfall on the cultivated extent of paddy in the mid country wet zone of Sri Lanka. National Conference in Climate change and its Impact on Agriculture, Forestry and Water Kandy, Sri Lanka, pp 41

Bouman, B.A.M. and van Laar, H.H. (2006). Description and evaluation of the rice growthmodel ORYZA2000 under nitrogen-limited conditions. Agric. Syst., 87, 249 - 273.

Chitranayana, R.D. and Punyawardena, B.V.R. (2010). Determination of onset time of rains during Yala and Maha seasons in major rice growing regions of Sri Lanka. Abstract of Papers. Proceedings Rice Congress 2010. Plant Genetic Resources Center, 2-3 December, Peradeniya, Sri Lanka.

De Costa, W.A.J.M. (2009). Impact of climate change on the long term variation in the water balance of different rainfall season in selected location. National Conference in Climate Change and its Impact on Agriculture, Forestry and Water, pp 51-52. Kandy, Sri Lanka.

DOA, (2014). Department of Agriculture, available at http://www.agridept.gov.lk/index.php/en/crop-recommendations/808[accessed on 2014.08.26] 
Gaydon, D.S., Probert, M.E., Buresh, R.J., Meinke, H., Suriadi, A., Dobermann, A., Bouman, B.A.M. and Timsina, J. (2012a). Rice in cropping systems - modeling transitions between flooded and non-flooded soil environments. Eur. J. Agron., 39, 9 - 24.

Gaydon, D.S., Probert, M.E., Buresh, R.J., Meinke, H. and Timsina, J. (2012b). Capturing the role of algae in rice crop production and soil organic carbon maintenance. Eur. J. Agron., $39,35-43$.

IPCC (2013). Data Distribution Centre. www.ipcc-data.org/ancillary/tar-bern.txi (accessed on: 04.07.13)

Jalota, S.K., Kaur, H. and Kaur, S. (2013). Impact of climate change scenarios on yield, water and nitrogen balance and use efficiency of rice-wheat cropping system. Agr. Water Manage., 116, 29 - 38

Keating, B.A., Carberry, P.S., Hammer, G.L., Probert, M.E., Robertson, M.J., Holzworth, D., Huth, N.I., Hargreaves, J.N.G., Meinke, H., Hochman, Z., McLean, G., Verburg, K., Snow, V., Dimes, J.P., Silburn, M., Wang, E., Brown, S., Bristow, K.L., Asseng, S., Chapman, S., McCown, R.L., Freebairn, D.M. and Smith, C.J., (2003). An overview of APSIM, a model designed for farming systems simulation. Eur J Agron, 18, 267 - 288.

Mapa, R.B., Somasiri S., Dassanayake, A.R. (2010). Soil of the Dry zone of Sri Lanka: Morphology, characterization and classification. Soil Science Society of Sri Lanka.

Punyawardena, B.V.R. (2002). Identification of the potential of growing season by the onset on seasonal rains: the study in the DL1 region of the north central dry zone. National Science Foundation of Sri Lanka. 30, 13 - 21.

Rathnayake, W.M.U.K. and Malaviarachchi, M.A.P.W.K. (2013). A crop simulation approach to determine optimum sowing dates for rainfed rice cultivation in the intermediate zone of Sri Lanka. In: Monograph on Rice Water Productivity in South Asia, Published by the SAARC Agriculture Centre, pp 238-242.

Samuel, T.D.M. (1991). Estimation of global radiation for Sri Lanka. Sol energy, 47, 333 337.

Suriyagoda, L.D.B. and Peiris, B.L. (2013). Does reduced application of nitrogen topdressing affect grain yield of rice. In: Monograph on Rice Water Productivity in South Asia, Published by the SAARC Agriculture Centre, 232-237.

Trenberth, K.E. and Jones, P.D. (2007). Observations: Surface and atmospheric climate change. In: Solomon, S., Qin, D., Manning, M., Chen, Z., Marquis, M., Averyt, K.B., Tignor, M., Miller, H.L. (Eds.), Climate Change 2007: The Physical Science Basis. Cambridge University Press, Cambridge, UK and New York, USA., 237.

Weerakoon, W.M.W. and De Costa, W.A.J.M. (2009).Impact of climate change on rice production of Sri Lanka. National Conference in Climate Change and its Impact on Agriculture, Forestry and Water Kandy, Sri Lanka, pp 6-7 